\title{
An electronic pressure-meter nociception paw test for mice
}

T.M. Cunha*, W.A. Verri Jr.*, G.G. Vivancos*, I.F. Moreira, S. Reis, C.A. Parada, F.Q. Cunha and S.H. Ferreira
Departamento de Farmacologia, Faculdade de Medicina de Ribeirão Preto, Universidade de São Paulo, Ribeirão Preto, SP, Brasil

\section{Correspondence \\ S.H. Ferreira \\ Departamento de Farmacologia \\ FMRP, USP \\ Av. Bandeirantes, 3900 \\ 14049-900 Ribeirão Preto, SP \\ Brasil \\ Fax: +55-16-633-0021 \\ E-mail: shferrei@fmrp.usp.br}

Research supported by CNPq, CAPES, FAPESP and PRONEX.

*These authors contributed equally to this study.

Received June 2, 2003

Accepted December 8, 2003

$\ldots \ldots \ldots \ldots \ldots \ldots \ldots$

\section{Abstract}

The aim of the present investigation was to describe and validate an electronic mechanical test for quantification of the intensity of inflammatory nociception in mice. The electronic pressure-meter test consists of inducing the animal hindpaw flexion reflex by poking the plantar region with a polypropylene pipette tip adapted to a hand-held force transducer. This method was compared to the classical von Frey filaments test in which pressure intensity is automatically recorded after the nociceptive hindpaw flexion reflex. The electronic pressure-meter and the von Frey filaments were used to detect time versus treatment interactions of carrageenininduced hypernociception. In two separate experiments, the electronic pressure-meter was more sensitive than the von Frey filaments for the detection of the increase in nociception (hypernociception) induced by small doses of carrageenin $(30 \mu \mathrm{g})$. The electronic pressure-meter detected the antinociceptive effect of nonsteroidal drugs in a dose-dependent manner. Indomethacin administered intraperitoneally $(1.8-15 \mathrm{mg} / \mathrm{kg})$ or intraplantarly $(30-300 \mu \mathrm{g} /$ paw) prevented the hypersensitive effect of carrageenin $(100 \mu \mathrm{g} /$ paw). The electronic pressure-meter also detected the hypernociceptive effect of prostaglandin $\mathrm{E}_{2}\left(\mathrm{PGE}_{2} ; 10-100 \mathrm{ng}\right)$ in a dosedependent manner. The hypernociceptive effect of $\mathrm{PGE}_{2}(100 \mathrm{ng})$ was blocked by dipyrone (160 and $320 \mu \mathrm{g} / \mathrm{paw})$ but not by intraplantar administration of indomethacin $(300 \mu \mathrm{g} / \mathrm{paw})$. The present results validate the use of the electronic pressure-meter as more sensitive than the von Frey filaments in mice. Furthermore, it is an objective and quantitative nociceptive test for the evaluation of the peripheral antinociceptive effect of anti-inflammatory analgesic drugs, which inhibit prostaglandin synthesis (indomethacin) or directly block the ongoing hypernociception (dipyrone).

\section{Introduction}

The type and site of application of a nociceptive stimulus, the sensitivity to analgesic drugs, as well as a typical innate behavioral response (end-point) characterize nociceptive tests. There is a growing consensus
Key words

- Hyperalgesia

- Nociception

- Indomethacin

- Dipyrone

- von Frey filaments in the literature that mice are the animals of choice for experimental studies, including immunological, physiopathological and inflammatory studies, because bioengineered specific reagents, such as recombinant cytokines and monoclonal antibodies, are available mainly for this species. Moreover, mice 
are also used for the generation of transgenic and knockout animals for different molecules, including immune and inflammatory mediators, and also for their specific receptors (1). The most popular test for the investigation of nociception in this animal species is the writhing test (2), quantified by the frequency of abdominal constrictions induced by inflammatory stimuli (i.e., acetic acid and zymosan). The tail flick and the formalin paw tests have also been extensively used (2). Although the writhing test is quite sensitive for detection of analgesic compounds, its therapeutic predictivity is inferior to the classical Randall and Selitto nociceptive test in rats (2). However, with the tests (except for the classical Randall and Selitto test), it is rather difficult to determine if an analgesic is causing antinociception by blocking the sensitization or by the activation of the nociceptors, phenomena that characterize inflammatory pain, which has a quite different mechanism. Sensitization of the nociceptors (hypernociception) is a metabotropic event involving at least the stimulation of the cAMP/PKA/ $/ \mathrm{Ca}^{2+}$ or the phospholipase/PKC/ $\mathrm{Ca}^{2+}$ pathways (3-8).

In recent years, the classical von Frey filaments test (9) has become popular among the mechanical tests used for rats and mice $(10,11)$. This mechanical test has an advantage over the writhing test and formalin test in mice because it distinguishes between the two components of inflammatory pain, i.e., sensitization and activation of the nociceptor.

In the present study, we standardized and evaluated an electronic version of the von Frey filaments test for mice. An electronic pressure-meter test has been described for use in humans and rats $(12,13)$. We induced an inflammatory process and sensitized the paws of mice with different doses of carrageenin and prostaglandin $\mathrm{E}_{2}\left(\mathrm{PGE}_{2}\right)$, respectively, to compare the sensitivity of the von Frey filaments and the electronic pressuremeter tests. We also used paws treated with carrageenin or with $\mathrm{PGE}_{2}$ to compare the sensitivity of the tests in detecting the analgesic action of indomethacin, a cyclooxygenase (COX) inhibitor or dipyrone, a direct-acting anti-hyperalgesic drug (14-16).

\section{Material and Methods}

\section{Animals}

The experiments were performed on 2530-g Swiss mice (University of São Paulo, Ribeirão Preto, SP, Brazil) housed in the animal care facility of the School of Medicine of Ribeirão Preto and taken to the testing room at least $1 \mathrm{~h}$ before the experiment. Food and water were available ad libitum. All behavioral testing was performed between 9:00 am and 4:00 pm. The mice were used only once. Animal care and handling procedures were in accordance with the International Association for Study of Pain (IASP) guidelines on the use of animals in pain research. Efforts were made to minimize the number of animals used and their suffering.

\section{von Frey filaments and electronic pressure- meter paw tests for mice}

In a quiet room, mice were placed in acrylic cages (12 × $10 \times 17 \mathrm{~cm}$ high) with a wire grid floor 15-30 $\mathrm{min}$ before testing. During this adaptation period, the paws were poked 2-3 times. Before paw stimulation, the animals were quiet, without exploratory movements or defecation and not resting on their paws. In these experiments, we used either a series of von Frey filaments (Stoelting, Chicago, IL, USA) with logarithmically incremental stiffness $(-1.17$ to $0.74 \mathrm{log}$ of force, g) or a pressure-meter which consisted of a handheld force transducer fitted with a $0.5 \mathrm{~mm}^{2}$ polypropylene tip (electronic von Frey anesthesiometer, IITC Inc., Life Science Instruments, Woodland Hills, CA, USA) (see accompanying paper, Ref. 17). The investiga- 
tor was trained to apply the filaments or the polypropylene tip perpendicularly to the central area of the hindpaw with a gradual increase in pressure. A tilted mirror below the grid provided a clear view of the animal's hindpaw. The test consisted of poking a hindpaw to provoke a flexion reflex followed by a clear flinch response after paw withdrawal. Each one of the von Frey filaments was applied for approximately 3-4 $\mathrm{s}$ to induce the end-point reflex. Testing was initiated with the filament handle marked 4.31, a value corresponding to $0.31 \mathrm{log}$ of force $(\mathrm{g})$ which is in the middle of the filament series. The response to this filament defined if a series of weaker or stronger filaments would be tested. The weakest filament able to elicit a response was taken to be the mechanical threshold (g).

The results are reported as the $\Delta \log$ of force $(\mathrm{g})$ calculated by subtracting the value of the measurements (log of force) after treatment from that of the first measurement for the von Frey test (before treatment). In the electronic pressure-meter test the intensity of the stimulus was automatically recorded when the paw was withdrawn. The maximal force applied was $18 \mathrm{~g}$. The stimulation of the paw was repeated until the animal presented two similar measurements. If the results were inconsistent (great difference in the baseline response compared to the other animals of the experiment), another animal was used. The results are reported as the $\Delta$ withdrawal threshold (g) which was calculated by subtracting the values obtained after the treatments from the first measurement (before treatment).

\section{Drugs}

Dipyrone and $\mathrm{PGE}_{2}$ were purchased from Sigma (St. Louis, MO, USA). Carrageenin was obtained from FMC Corporation (Philadelphia, PA, USA), and indomethacin from Prodome Química e Farmacêutica (São Paulo, SP, Brazil).

Carrageenin and dipyrone were diluted in sterile saline. A stock solution of $\mathrm{PGE}_{2}$ was prepared in $10 \%$ ethanol, and further dilutions were made in saline; the final concentration of ethanol was $1 \%$. Indomethacin was diluted in $0.1 \mathrm{M}$ Tris- $\mathrm{HCl}$ buffer, $\mathrm{pH}$ 8.0. Tris- $\mathrm{HCl}$ buffer alone was used for the control groups.

\section{Drug administration}

For local administration, drugs were injected subcutaneously into the plantar region of the hindpaws. A hypodermic 26-G needle was inserted into the skin of the second footpad (to avoid back flow) and the tip of the needle was introduced until the central area of the hindpaw, in the same place where filaments or the tip of the pressure-meter were applied. A volume of $25 \mu 1$ was administered. For systemic treatment, drugs were injected intraperitoneally in a volume of 200 $\mu 1$. Doses were calculated based on animal weight.

\section{Statistical analysis}

Two-way analysis of variance (ANOVA) was used to compare the groups and doses over all times. The factors analyzed were treatments, time and time $v s$ treatment interaction. When a significant time $v s$ treatment interaction was detected, one-way ANOVA followed by the Tukey test was performed for each time in order to distinguish dose effects. One-way ANOVA followed by Tukey test was also used for dose-response curves for a single time point. Results with $\mathrm{P}$ $<0.05$ were considered to be significant.

\section{Results}

\author{
Comparison of the sensitivity for the \\ detection of carrageenin-induced mechanical \\ hypernociception by the electronic pressure- \\ meter and the von Frey filaments tests
}

Figure 1 shows that the carrageenin- 
Figure 1. Time course of the hypernociception induced by intraplantar injections of carrageenin $(\mathrm{Cg})$ in mice detected with the electronic pressuremeter (A) and von Frey filaments (B). Saline was injected intraplantarly in the control group. The results are reported as the mean \pm SEM for 4-5 animals per group and are representative of two separate experiments. ${ }^{*} P<0.05$ indicates a significant difference between time-points indicated by the brackets. $\mathrm{ns}=$ nonsignificant (two-way ANOVA and one-way ANOVA followed by the Tukey test).

Figure 2. Effect of indomethacin on carrageenin-induced hypernociception in mice measured with the electronic pressuremeter. Animals were pretreated with indomethacin $30 \mathrm{~min}$ before intraplantar injection of carrageenin $(100 \mu \mathrm{g})$. Indomethacin was injected intraperitoneally ( $\mathrm{A}$, systemic, $1.8,5$ and $15 \mu \mathrm{g} / \mathrm{kg}$ ) or subcutaneously into the mouse paw (B, local, 30, 100 and 300 $\mu \mathrm{g} /$ paw or contralateral (cl) paw, 100 and $300 \mu \mathrm{g} / \mathrm{paw}$ ). Tris- $\mathrm{HCl}$ buffer (Tris) was injected in the control groups. The bars indicate the withdrawal threshold $3 \mathrm{~h}$ after carrageenin administration. The results are reported as the mean \pm SEM for 5 animals per group and are representative of two separate experiments. ${ }^{*} \mathrm{P}<$ 0.05 compared to control (Tris) (one-way ANOVA followed by the Tukey test). induced hypernociception was detected by both the electronic pressure-meter (panel A; $10,30,100$ and $300 \mu \mathrm{g} / \mathrm{paw})$ and the classical von Frey filaments (panel B; 30, 100 and $300 \mu \mathrm{g} / \mathrm{paw}$ ) tests. There was a significant increase in paw hypernociception with a time versus treatment interaction (ANOVA). The hypernociception induced by a low dose of carrageenin $(30 \mu \mathrm{g} / \mathrm{paw})$ was detected by the electronic pressure-meter but not by the von Frey filaments as a significant effect.

Detection of the local and systemic effects of indomethacin on the carrageenin-induced hypernociception by the electronic pressuremeter test

The systemic (panel A) and local (panel
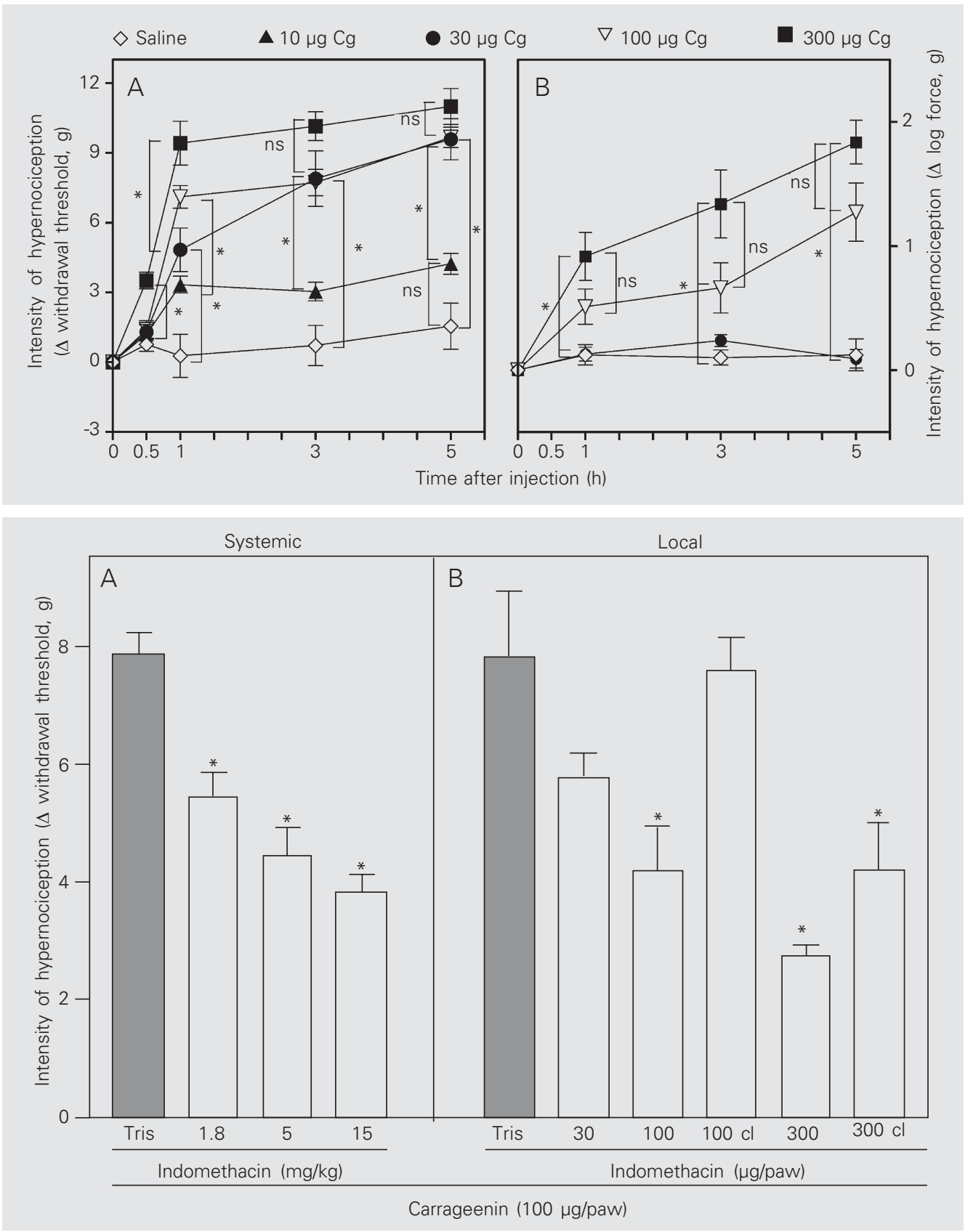
B) inhibitory effects of indomethacin on the hypernociception induced by carrageenin $(100 \mu \mathrm{g})$ is shown in Figure 2. Both systemic $(1.8,5$ and $15 \mathrm{mg} / \mathrm{kg}$, intraperitoneally) and local (30, 100 and $300 \mu \mathrm{g} / \mathrm{paw})$ administration of indomethacin produced a dose-dependent (ANOVA) blockade of the hypernociceptive state induced by carrageenin (100 $\mu \mathrm{g} / \mathrm{paw})$. Although the local administration of indomethacin at a dose of $300 \mu \mathrm{g} / \mathrm{paw}$ had a systemic effect on carrageenin-induced hypernociception, the dose of $100 \mu \mathrm{g} / \mathrm{paw}$ had only a local effect since it was not able to inhibit the carrageenin-induced hypernociception in the contralateral paw.

Dose-response curve for the hypernociception induced by intraplantar injection of $\mathrm{PGE}_{2}$ in mice and its blockade by dipyrone but not by indomethacin

The electronic pressure-meter was able to detect the statistically significant intraplantar effect of the three doses of $\mathrm{PGE}_{2}(10$,
30 and 100 ng; Figure 3, ANOVA). Paw hypernociception tended to increase with time (particularly with small doses) and there was a significant interaction between time and the different treatments (Figure 3A, ANOVA). Dipyrone (80, 160 and $320 \mu \mathrm{g}$; Figure 3C), but not indomethacin (Figure 3B), inhibited the $\mathrm{PGE}_{2}$-induced (100 ng) hypernociception in a dose-dependent manner (ANOVA).

\section{Discussion}

In the present study, we have used the word hypernociception (increased nociception) to describe the behavioral response induced by the application of von Frey filaments or the electronic pressure-meter. The terms allodynia and hyperalgesia describe distinct nociceptive symptoms in man $(18,19)$. von Frey filaments have been used to measure increased experimental nociceptor sensitivity referred to as allodynia or hyperalgesia by different investigators. In

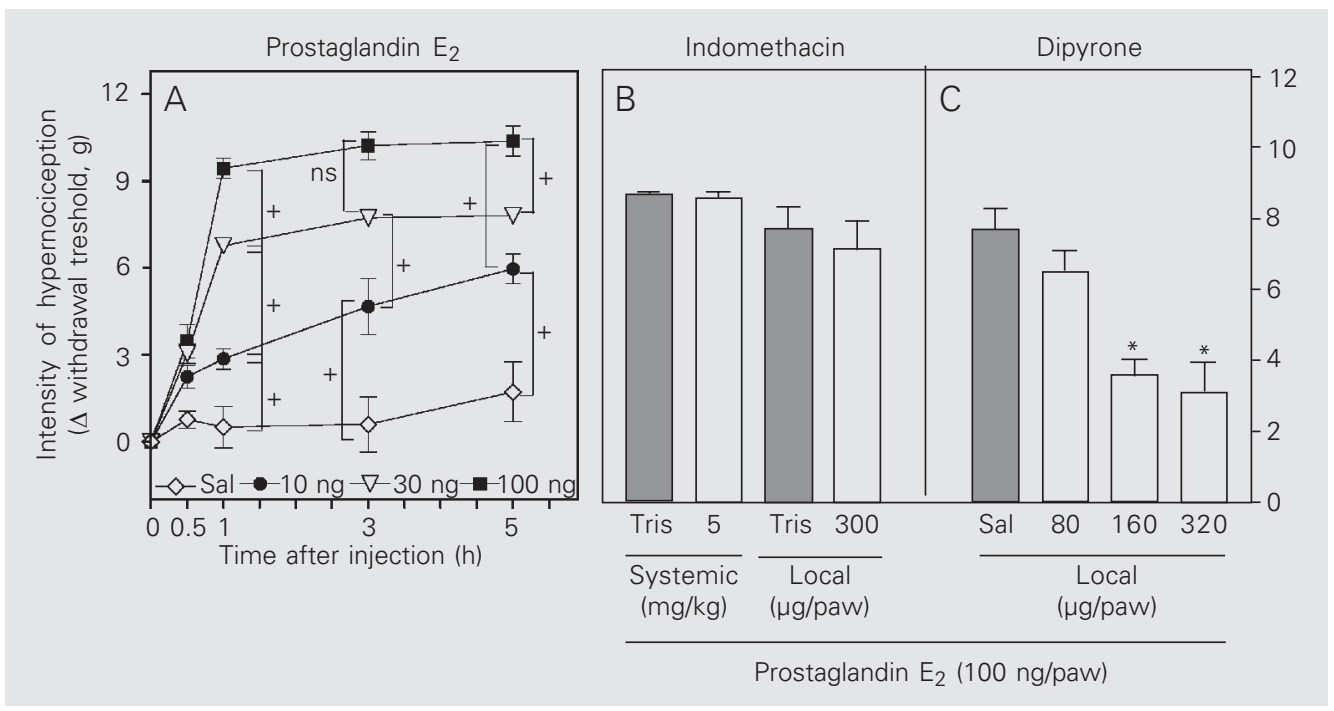

Figure 3. Dose-response curve for the hypernociception induced by intraplantar injection of prostaglandin $E_{2}$ $\left(\mathrm{PGE}_{2}\right)$ in mice and its blockade by dipyrone but not by indomethacin measured with the electronic pressuremeter. Panel $A$ shows the time course of the PGE 2 -induced hypernociception at the doses of 10, 30 and $100 \mathrm{ng} /$ paw. In Panel B, dipyrone (80, 160 and $320 \mu \mathrm{g} /$ paw) or saline (Sal) was injected $2 \mathrm{~h}$ after PGE 2 (100 ng). In Panel C, pretreatment with indomethacin $(300 \mu \mathrm{g})$ or Tris- $\mathrm{HCl}$ buffer (Tris) was performed 30 min before injection of the hypersensitizing agent. Measurements were made $3 \mathrm{~h}$ after $\mathrm{PGE}_{2}$ in $A$ and $B$. The results are reported as the mean \pm SEM for $4-5$ animals per group and are representative of two separate experiments. ${ }^{+} P<0.05$ indicates a significant difference between points ( $\mathrm{A}$, two-way ANOVA and one-way ANOVA followed by the Tukey test); ${ }^{*} \mathrm{P}<0.05$ compared to control (Sal or Tris; B and C, one-way ANOVA followed by the Tukey test). 
fact, so far there is no demonstration that these symptoms describe different second messenger events in the inflammatory response. The use of the terms hypersensitivity or hyperexcitability was also avoided because they have specific meanings in immunology and electrophysiology, respectively.

We evaluated the efficacy of the electronic pressure-meter to detect nociceptor hypernociception in mice. This commercially available instrument (electronic von Frey) is similar to that successfully used to quantify neuropathic allodynia (13) and inflammatory hypernociception in rats (17). The electronic method has several advantages over the classical von Frey filaments: a) reduction of the number of attempts required to evaluate the nociceptive threshold; b) elimination of the problems of filament standardization; c) stimulation of areas of equal size (the area varies with the diameter of the von Frey filaments), d) the end-point is automatically recorded $(12,20)$.

Carrageenin-induced hypernociception could be detected in the inflamed paws of the mice by poking the paws with the von Frey filaments and the electronic pressure-meter. The electronic pressure-meter detected hypernociception as early as $1 \mathrm{~h}$ after the injection of carrageenin at the lower doses, which was not detected by the von Frey filaments.

The usefulness of the electronic pressure-meter for the study of analgesics in mice was demonstrated with indomethacin and dipyrone. Indomethacin is a COX inhibitor and dipyrone has specific antinociceptive effects on $\mathrm{PGE}_{2}$-induced hypernociception, which are not shared by COX inhibitors. The activation of the arginine-NOcGMP pathway contributes to dipyrone-induced spinal and peripheral analgesia (14) via opening of $\mathrm{K}^{+}$ATP-sensitive channels (15).
The electronic pressure-meter detected the systemic and local antinociceptive effects of a standard COX inhibitor, indomethacin, in a dose-dependent manner. The electronic test differentiated among increasing doses of $\mathrm{PGE}_{2}$ although no time discrimination between 1 and $5 \mathrm{~h}$ after administration was observed. In general, hypernociception tended to be more intense at later times. Although indomethacin (as expected) showed no local effect on $\mathrm{PGE}_{2}$-induced hypernociception, dipyrone showed a dose-dependent antinociceptive effect. Thus, this technique is capable of differentiating between drugs that prevent the development of hypernociception (blockade of carrageenin hypernociception) and those which directly antagonize ongoing hypernociception, i.e., dipyrone.

A clear dissociation in time between the hypernociceptive and the nociceptive stimuli, an easily defined and recorded end-point induced by the nociceptive stimulus, and the ability to differentiate between different classes of peripheral analgesics are essential characteristics of a useful test for the development of new analgesics as well as for the investigation of inflammatory pain mechanisms. In the present investigation, we showed that the electronic pressure-meter test in mice fulfills all of these basic conditions.

\section{Acknowledgments}

We wish to thank Iramirton Figuerêdo Moreira and Simone Reis, summer visiting students (Academia Brasileira de Ciências) for their assistance, and Ieda Regina dos Santos Schivo and Sérgio Roberto Rosa for excellent technical support. The authors also want to express their gratitude to Prof. Francisco Silveira Guimarães for useful advice about statistical analysis. 


\section{Referentes}

1. Mogil JS \& Grisel JE (1998). Transgenic studies of pain. Pain, 77: 107-128.

2. Le Bars D, Gozariu M \& Cadden SW (2001). Animal models of nociception. Pharmacological Reviews, 53: 597-652.

3. Taiwo YO \& Levine JD (1989). Contribution of guanine nucleotide regulatory proteins to prostaglandin hyperalgesia in the rat. Brain Research, 492: 400-403.

4. Cunha FQ, Teixeira MM \& Ferreira SH (1999). Pharmacological modulation of secondary mediator systems - cyclic AMP and cyclic GMP - on inflammatory hyperalgesia. British Journal of Pharmacology, 127: 671-678.

5. Ferreira SH \& Nakamura M (1979). I-Prostaglandin hyperalgesia: a cAMP/Ca ${ }^{2+}$ dependent process. Prostaglandin, 18: 179-190.

6. Lynn B \& O'Shea NR (1998). Inhibition of forskolin-induced sensitization of frog skin nociceptors by the cyclic AMP-dependent protein kinase A antagonist H-29. Brain Research, 780: 320-362.

7. Taniguchi K, Shinjo K, Mizutani M, Shimada K, Ishikawa T, Menniti FS \& Nagahisa A (1997). Anti-nociceptive activity of CP-101,606, NMDA receptor NR2B subunit antagonist. British Journal of Pharmacology, 122: 809-812.

8. Coderre TJ (1992). Contribution of protein kinase $C$ to central sensitisation and persistent pain following tissue injury. Neuroscience Letters, 140: 181-184.

9. von Frey M (1896). Untersuchunger über die Sinnesfunctionen der menschlichen Haut. Bandes der Abhandlungen der mathematischphysischen Classe der Königl. Sächsischen Gesellschaft der Wissenschaften, 23: 175-266.

10. Prado WA, Schiavon VF \& Cunha FQ (2002). Dual effect of local application of nitric oxide donors in a model of incision pain in rats. European Journal of Pharmacology, 441: 57-65.

11. Shimoyama M, Tanaka K, Hasue F \& Shimoyama N (2002). A mouse model of neuropathic cancer pain. Pain, 99: 167-174.

12. Jensen K, Andsersen HO, Olesen J \& Lindblom U (1986). Pressure-pain threshold in human temporal region. Evaluation of a new pressure algometer. Pain, 25: 313-323.

13. Möller KÄ, Johansson B \& Berg OG (1998). Assessing mechanical allodynia in the rat paw with a new electronic algometer. Journal of Neuroscience Methods, 84: 41-47.

14. Lorenzetti BB \& Ferreira SH (1996). Activation of the arginine-nitric oxide pathway in primary sensory neurons contributes to dypironeinduced spinal and peripheral analgesia. Inflammation Research, 45: 308-311.

15. Alves D \& Duarte I (2002). Involvement of ATP-sensitive K(+) channels in the peripheral antinociceptive effect induced by dipyrone. European Journal of Pharmacology, 24: 47-52.

16. Ferreira SH, Moncada S \& Vane JR (1973). Prostaglandins and the mechanism of analgesia produced by aspirin-like drugs. British Journal of Pharmacology, 49: 86-97.

17. Vivancos GG, Verri Jr WA, Cunha TM, Schivo IRS, Parada CA, Cunha FQ \& Ferreira SH (2004). An electronic pressure-meter nociception paw test for rats. Brazilian Journal of Medical and Biological Research, 37: 391-399

18. Onttonen T \& Pertovaara A (2000). The mechanical antihyperalgesic effect of intrathecally administered MPV-2426, a novel alpha2adrenoceptor agonist, in a rat model of postoperative pain. Anesthesiology, 92: 1740-1745

19. Vrinten DH, Gispen WH, Groen GJ \& Adan RA (2000). Antagonism of the melanocortin system reduces cold and mechanical allodynia in mononeuropathic rats. Journal of Neuroscience, 20: 81318137.

20. Greenspan JD \& Taylor D (1990). Thresholds for the perception of sharpness and mechanical pain. Pain, 5 (Suppl): S313. 